\title{
DENSIDADES DO SISTEMA FINANCEIRO: USO CORPORATIVO E DESIGUALDADES REGIO- NAIS DO TERRITÓRIO BRASILEIRO
}

\section{Financial system densities: the corporative use and regional inequalities of Brazilian territory}

\author{
Ricardo Alberto Scherma \\ Doutorando em Geografia, UNESP \\ Rio Claro/SP - Brasil \\ schermaricardo@bol.com.br
}

Samira Peduti Kahil

Prof $^{a}$. Dr ${ }^{\mathrm{a}}$. dos cursos de Graduação e Pós-Graduação em Geografia, UNESP

Rio Claro/SP - Brasil

jckc@uol.com.br

Artigo recebido para publicação em 08/09/2010 e aceito para publicação em 11/04/2011

RESUMO: Diante da histórica situação geográfica de desigualdade regional brasileira, procuramos destacar a questão da desigual distribuição do dinheiro, analisando tanto a instalação dos fixos bem como a dinâmica dos fluxos do sistema financeiro em território nacional. Demonstramos a territorialização do sistema financeiro, por meio de suas agências bancárias, que controlam hoje a dinâmica dos fluxos monetários no território brasileiro. Contudo, apenas o conhecimento dessas formas geográficas, sua quantificação e topologia de nada nos adiantariam se não investigássemos os fluxos de crédito e de depósitos, revelando as desigualdades resultantes do uso corporativo do território brasileiro. Por último, levantamos dados e realizamos revisão bibliográfica que demonstra a consolidação da cidade de São Paulo como centro financeiro do território nacional.

Palavras-Chave: Uso do território. Densidades financeiras. Centralidade. Cidade de São Paulo (SP).

ABSTRACT: On the historical geographic situation of Brazilian regional inequality, we intended to highlight the question of unequal distribution of money, analyzing the fixed installation and the dynamic of fluxes of the financial system in national territory. We demonstrated the territorialization of the financial system, by its banks, that control nowadays the monetary fluxes dynamic in Brazilian territory. Though, only the knowledge of these geographical forms, their quantification and topology wouldn't help us if we didn't investigate the fluxes of credit and deposit, showing the inequalities that are result of the corporative use of Brazilian territory. At last, we collected data and reviewed a bibliography that demonstrates the setting of the city of São Paulo as the financial center in national territory.

Keywords: Use of territory. Financial densities. Centrality. City of São Paulo (SP) 


\section{INTRODUÇÃO}

As transformações na dinâmica do processo de acumulação do capital, ocorridas a partir dos anos 70 no Brasil, muito ligadas, ordenadas segundo as transformações na dinâmica econômica mundial, acabam, do ponto de vista das dinâmicas territoriais, resultando em aprofundamento dos desequilíbrios regionais, já que o território, organizado também segundo os mesmos interesses (privados), acaba por constituir-se em um meio técnico-científico e informacional seletivamente funcional às atividades hegemônicas do capital e da política, também mundiais. Estamos chamando de meio técnico-cientifico-informacional as manifestações geográficas decorrentes dos mais novos sistemas técnicos, cujos subsistemas de objetos técnicos tendem a ser, ao mesmo tempo, técnicos e informacionais, "já que graças à extrema intencionalidade de sua produção e de sua localização, eles surgem como informação; e, na verdade, a energia principal de seu funcionamento é também a informação" (SANTOS, 1996, p.190). Esse novo meio técnico-informacional é usado e serve principalmente ao capital hegemônico do sistema financeiro e se instala no território para, exatamente, servir aos seus próprios desígnios.

A formação do território brasileiro é uma história de desigualdades. Desigualdades sócio-econômicas que se expressam primeiro como desigualdades territoriais - a desigual repartição do trabalho e da riqueza, responsável também por uma histórica tensão política. É dessa desigual repartição dos recursos territoriais e do uso corporativo do espaço da nação que resta um território alienado para maior parte da sociedade brasileira. A formação de uma nova configuração do território usado pelo sistema financeiro, consolidada a partir dos anos 90 , acentuou as graves desigualdades regionais existentes no Brasil.

Essas desigualdades regionais podem ser identificadas empiricamente segundo as densidades técnico-políticas de cada região, pois "o território mostra diferenças de densidades quanto às coisas, aos objetos, aos homens, ao movimento das coisas, dos homens, das informações, do dinheiro e também quanto às ações" (SANTOS; SILVEIRA, 2006, p.260). É no território que encontramos maior ou menor presença de próteses, maior ou menor densidade de dinheiro, maior ou menor acesso ao crédito, maior ou menor presença do Estado (SANTOS; SILVEIRA, 2006, p.261).

Entre outras variáveis, a presença das agências bancárias nos lugares pode também nos mostrar como há um uso seletivo do território, o aprofundamento das injustas desigualdades às quais está sujeita a sociedade brasileira e, conseqüentemente, as tensões políticas daí decorrentes. Presente como um sistema de objetos geográficos animados por sistemas de ações, esses fixos seletivamente instalados no território nacional e seus respectivos fluxos impõem uma dinâmica ao território, cujo ritmo segue àqueles interesses das grandes corporações do sistema financeiro. Pierre Monbeig já assinalava a importância dos estudos sobre a organização bancária no Brasil, mostrando que "as organizações bancárias fazem parte do conjunto de elementos que constituem um complexo geográfico" (MONBEIG, 1957, p.29).

Para Monbeig (1957), o capital empregado nas regiões deve ser considerado como um dos fatores essenciais para o entendimento das transformações que ocorrem na paisagem, portanto, o entendimento da lógica de atuação dos bancos revela como "[...] sua ação financeira, pelas atividades que nascem e vivem com seu auxílio, pelas relações que estabelecem e mantêm, concorrem poderosamente para animar a vida regional". Portanto, nos diz Monbeig, importa "[...] examinar o volume dos negócios de cada banco [...], indagar qual o volume médio dos depósitos e dos empréstimos" (MONBEIG, 1957, p.224).

Para Jean Labasse (1974, p.54) a densidade bancária é definitivamente a expressão do grau de desenvolvimento da economia monetária. Em ' $L$ 'Espace Financier", Labasse demonstra em um dos capítulos as densidades bancárias encontradas na Europa, como na África, apontando densidades muito desiguais. Em 1966, a Suíça possuía 1 guichê bancário para cada 1.200 mil habitantes, enquanto, no Senegal, em 1970, a densidade era de 1 guichê para cada $134.000 \mathrm{mil}$ habitantes (LABASSE, 1974, p.52).

Já Milton Santos e Maria Laura Silveira (2006, p.185) afirmam que as expansões e retrações do subsistema bancário nacional seriam uma manifestação do comando do sistema financeiro sobre a economia, bem como, comando do território, já que a produção 
e o consumo se tornam cada vez mais dependentes das condições e da oferta de crédito. O sistema financeiro nacional, nesta contemporaneidade, certamente exerce função de comando, pois, até mesmo políticas de desenvolvimento, ditas públicas, estão sendo administradas pelo sistema. Isso certamente nos ajuda a explicar a expansão do sistema financeiro, tanto para os lugares de já alta densidade técnica e informacional, bem como, alcançando já as regiões em que hoje se instalam as mais modernas atividades agrícolas - a região central do Brasil, visto que as instituições bancárias respondem, em grande medida, pelo sistema de circulação e movimento do dinheiro no país.

Procuraremos demonstrar a densidade de agências, depósitos, crédito e, por fim, assegurar a idéia de que a cidade de São Paulo é o centro financeiro do território brasileiro, uma vez que as densidades financeiras encontradas na capital paulista na atualidade são muito superiores às de qualquer outro estado da federação. Para fazermos tal análise, usamos a regionalização proposta por Milton Santos e Maria Laura Silveira (2006), na obra “O Brasil”, em que o território brasileiro pode ser regionalizado segundo a difusão diferencial do meio técnico-científico-informacional e heranças do passado, o que torna possível delimitar quatro grandes regiões, sendo elas: a Região Concentrada, Nordeste, Centro-Oeste e a Amazônia.

\section{DENSIDADE E RAREFAÇÃO DAS AGÊNCIAS BANCÁRIAS NO TERRITÓRIO BRASILEIRO}

Hoje, as agências bancárias formam uma rede complexa que dá suporte ao processo de travessia e permanência de fluxos financeiros em todo o território nacional. Por meio da rede de agências, os bancos captam os capitais presentes em cada lugar, e são elas que permitem que a intermediação financeira se desenvolva. Além da captação, esse sistema de agências tem a função de conduzir fluxos de dinheiro para os lugares, fator este que pode explicar sua maior ou menor presença no território, considerando que a sua instalação está, entre outros fatores, determinada pelo dinamismo econômico do lugar. Entre 1972 e 1996, houve um crescimento de $110 \%$ no número de agências bancárias distribuídas no país, perfazendo uma constelação de 16.224 agências bancárias em
1996. Dez anos mais tarde, em 2006, esse número alcançaria a marca de 17.743 e em 2007, 18.308 agências. Diante destes números, pode-se afirmar que "essa expansão foi, em grande parte, comandada pelos bancos privados, que se alastraram pelo território em virtude das oportunidades de financiar uma produção e uma circulação altamente dependente de capitais adiantados" (SANTOS; SILVEIRA, 2006, p.186).

Contudo, apesar desse vertiginoso crescimento no número de agências e a expansão para áreas de ocupação periférica, possível, sobretudo, pelas conquistas da técnica, da ciência e da informação, o território brasileiro ainda apresenta, neste início de século, grandes desigualdades, pois, como diz Georges Benko "somente algumas regiões são ganhadoras" (BENKO; LIPIETZ, 1994). A reorganização do sistema bancário, iniciada após 1988, e o ajuste dos bancos a uma economia com índices baixos de inflação resultaram, segundo Leila C. Dias (2005, p.58), numa configuração espacial muito mais seletiva, sobretudo no interior das regiões mais pobres do país, especialmente Norte e Nordeste, onde vastos territórios foram completamente varridos do mapa bancário. Essas regiões mais pobres e menos povoadas voltariam a ser interesse do sistema financeiro somente diante da possibilidade normativa de novas formas de topologia bancária: os correspondentes bancários, as lojas de crédito e o banco postal. A Região Concentrada, formada pelos estados de Santa Catarina (884 agências), Rio Grande do Sul (1.473 agências), Paraná (1.275 agências), São Paulo (6.017 agências), Rio de Janeiro (1.721 agências), Espírito Santo (374 agências) e Minas Gerais (1.874 agências) concentrava, em 2007, 13.618 agências, $76,75 \%$ da totalidade da rede de agências bancárias do país. Mesmo que grande parte da população brasileira, cerca de 57\%, habite os estados da Região Concentrada, a densidade de agências por habitante nessa região continua sendo maior do que em outras regiões do Brasil.

Calculamos o número de agências bancárias por habitantes segundo as regiões do Brasil e encontramos densidades muito desiguais. A Região Concentrada apresenta a densidade de 1 agência para cada 7.741 habitantes, sendo a região do país com maior número desses fixos geográficos por habitante, seguida pela Região Centro-Oeste, que apresenta a 
densidade de 1 agência para cada 9.790 habitantes. As maiores rarefações, no entanto, encontram-se nas Regiões da Amazônia e Nordeste, em que é possível constatar 1 agência para cada 21.355 habitantes e 19.620 habitantes, respectivamente. Nestas Regiões, o número de agências por habitantes é quase três vezes menor em relação à densidade constatada na Região Concentrada.

\section{DENSIDADE E RAREFAÇÃO DO CRÉDITO EM SUBESPAÇOS DO TERRITÓRIO BRASILEIRO}

No Brasil contemporâneo, bem como no mundo, graças aos complexos sistemas de objetos técnicos e de ações, fluxos materiais e imateriais circulam intensamente e dinamizam a vida de relações entre os lugares. As empresas financeiras são muito responsáveis pela promoção generalizada de desintegrações, desigualdades e seletividades territoriais. Agentes hegemônicos da economia mundial, as empresas financeiras impõem e regem, segundo seus próprios ritmos, a dinâmica do modo de desenvolvimento do capitalismo contemporâneo.

No comando dos processos produtivos, comando orquestrado segundo a lógica geral de maior aplicação financeira em um número cada vez menor de lugares, selecionados segundo essa mesma lógica concentradora e centralizadora do poder econômico, esses agentes hegemônicos do sistema financeiro terminam por fragmentar ainda mais os territórios nacionais (ARROYO, 1999, p.25). Márcio Cataia, a respeito das desigualdades e da tecnificação do território brasileiro, afirma que:

Em todas as escalas o signo monetário está presente: organizando ou desorganizando o território. Maiores investimentos em um lugar podem significar maior produtividade espacial e inserção na discursada modernização. Menores investimentos ou mesmo ausência podem significar a estagnação, o desemprego (CATAIA, 1996, p. 173).

As decisões políticas de, a qualquer custo, instrumentalizar o território como recurso para atrair capitais e inserir-se econômica e competitivamente no mercado mundial, têm reforçado as já históricas desigualdades regionais. Seguindo a lógica da competitividade e seletividade do novo modo de desenvolvimento do capitalismo contemporâneo, as políticas de concessão de crédito, sejam aquelas disponibilizadas pelo Estado através de programas de desenvolvimento do Banco Nacional de Desenvolvimento Econômico e Social - BNDES -, ou o crédito disponibilizado pelos conglomerados financeiros privados, são políticas diretivas dos investimentos para determinadas atividades e lugares que lhes são vantajosos, ignorando todos os demais lugares e demandas sociais.

A seletividade territorial na concessão dos créditos possibilitou, por exemplo, a modernização da agricultura e da pecuária, que se inicia no Brasil a partir da década de 70 , processo esse que resultou na constituição de um meio geográfico desigual, pois "foi induzida - pelos interesses dos grupos hegemônicos - e concentrada em algumas propriedades e regiões" (RAMOS, 2001, p.384).

As operações de financiamentos via BNDES seguem a mesma lógica: em 2007 o desembolso anual do sistema BNDES foi de 37,581 bilhões de reais, destinados à região Sudeste, 12,772 bilhões à região Sul, 5.754 bilhões de reais à região Centro-Oeste, 5,332 bilhões de reais ao Nordeste e 3,460 bilhões de reais à região Norte do país. Do total dos desembolsos, apenas 6,048 bilhões de reais foram destinados a micro e pequenas empresas, 6,078 bilhões de reais às empresas de médio porte e 3,939 bilhões de reais a pessoas físicas, sendo destinados às grandes empresas 48, 825 bilhões de reais. Considerando a desigual distribuição e concessão de crédito, ficam evidentes as persistentes e cada vez mais profundas desigualdades entre as regiões brasileiras.

A Região Concentrada, uma região já ganhadora e privilegiada "pela implantação mais consolidada dos dados da ciência, da técnica e da informação" (SANTOS; SILVEIRA, 2006, p.269), recebeu, durante o ano de 2007, $84 \%$ do total nacional de crédito concedido. Cabe destacarmos que o total da concessão de crédito no estado de São Paulo, no mesmo período (2007), foi de 496 bilhões de reais, valor esse quase dez vezes maior que aqueles concedidos aos demais estados da Região Concentrada e 58,73\% do valor total nacional. 
A região Centro-Oeste, uma "área de ocupação periférica recente" (SANTOS; SILVEIRA, 2006, p.271), onde uma vida de relações não intensa tende a ser substituída pelos novos ritmos de um explosivo mundo de negócios que aí se instala e se articula após os anos 70, provocando a expansão do meio técnico-científico-informacional (GOMES, 2001, p.312), aparece em segundo lugar na repartição dos recursos financeiros, com uma participação de 8,19\% em relação ao total nacional. Essa posição se dá, sobretudo, pelo desenvolvimento da moderna agricultura nesta região, atividade que necessita de elevadas somas de dinheiro antecipado para que a produção seja possível.

O Nordeste brasileiro, região com numerosos núcleos populacionais, contudo, precariamente integrados ao processo das expansões do meio técnico-científico-informacional, que se constitui nessa região apenas como manchas ou pontos (GOMES, 2001, p.320), mesmo sendo uma área de povoamento antigo e abrigando, ainda hoje, aproximadamente $28 \%$ da população nacional, e que, portanto deveria receber mais crédito, segundo a lógica seletiva do desenvolvimento capitalista, recebeu apenas $6,6 \%$ do total do volume de crédito concedido no país em 2007.

Assim também a Amazônia, "região de rarefações demográficas herdadas e baixas densidades técnicas" (SANTOS; SILVEIRA, 2006, p.272), foi a região de menor participação no que se refere à concessão de crédito no país: apenas $1,4 \%$ do total nacional; três de seus estados - Acre, Amapá e Rondônia — receberam menos de 1 bilhão de reais, são os estados que apresentam as maiores rarefações financeiras.

\section{DENSIDADE E RAREFAÇÃO DOS DEPÓSITOS EM SUBESPAÇOS DO TERRITÓRIO BRASI- LEIRO}

Se os lugares são selecionados para a concessão de crédito para fins produtivos e de consumo, o mesmo não ocorre para a captação de depósitos, para o qual as empresas financeiras usam o território como um todo. A voracidade de arrecadação do sistema bancário move o sistema financeiro para áreas de baixas densidades técnicas, o que exige novas formas de intermediação bancária diferente daquela forma submetida à rigidez das normas que condicionam $o$ funcionamento de uma agência bancária.

A Região da Amazônia, tendo uma rede de 624 agências, foi responsável por uma captação de $\mathrm{R} \$ 15,34$ bilhões de reais em depósitos e poupança no ano de 2007. Quando consideramos essa captação em relação à população, esse número representa baixa densidade de depósitos por habitante (R\$ 1,14 mil por habitante).

As captações na Região Centro-Oeste, onde encontramos uma constelação de 1.463 agências bancárias, arrecadaram, em 2007, 78 bilhões de reais entre depósitos e poupança. A densidade de depósitos por habitante foi de R $\$ 5,44$ mil; no entanto, se desconsiderarmos o Distrito Federal, lugar com alta densidade financeira por habitante, essa região passa a apresentar densidade de $\mathrm{R} \$ 1,7$ mil por habitante.

A Região Nordeste foi responsável por captar 73,23 bilhões de reais durante o ano de 2007, com uma população em torno de 51,014 milhões de pessoas e 2600 agências bancárias. Essa captação, se considerada segundo a densidade de depósitos por habitante, veremos que foi de $\mathrm{R} \$ 1,43$ mil.

Com a maior densidade financeira do país, a Região Concentrada foi responsável pela captação de 618,57 bilhões de reais em depósitos e poupança no ano de 2007. A densidade de depósitos por habitantes nessa região foi de $\mathrm{R} \$ 5,86$ mil e denuncia graves concentrações do dinheiro no país. O estado de São Paulo apresenta a densidade de R $\$ 8,6$ mil por habitante, seguido do Rio de Janeiro, com R \$ 5,4 mil por habitante; os demais estados da região apresentam densidades entre $\mathrm{R} \$ 2,9$ e $\mathrm{R} \$ 4,89$ mil por habitante.

Apesar de na Região Concentrada serem feitas a maior parte das transações financeiras e ser essa Região portadora das maiores densidades de depósitos por habitantes, encontramos dentro deste recorte regional estados com captações médias em relação aos demais estados da federação. É o caso de Santa Catarina - 19,08 bilhões de reais - e Espírito Santo - 11,59 bilhões de reais - que apresentam valores menores do que os dos estados da Bahia - 20.02 bilhões de reais - e Ceará - 15,47 bilhões de reais. No entanto, se calcularmos a densidade de depósitos por habitante, esses estados da Região Concentrada apresentam densidades superiores, sendo elas, R\$ 3,25 mil por habitante em Santa Catarina e R \$ 3,4 
mil por habitante no Espírito Santo, contra R \$ 1,4 mil por habitante na Bahia e R \$1,9 mil por habitante no Ceará. Essas desigualdades evidenciam diferenças no uso do território pelo sistema financeiro, mostrando inclusive a desigual repartição da riqueza.

\section{LÓGICAS DE CIRCULAÇÃO DO DINHEIRO: "REGIÕES PERDEDORAS" E "REGIÕES GA- NHADORAS"}

Descrevemos o quadro estático do sistema financeiro no Brasil. Contudo há necessidade de analisarmos as variáveis - crédito e depósitos - de forma dinâmica e conjugada para encontrarmos as lógicas de circulação do dinheiro no território. De acordo com Fabio B. Contel (2006, p.216), a partir da análise dos passivos e ativos regionais é possível determinar "regiões ganhadoras", isso para usarmos a terminologia de Benko e Alain Lipietz (1994).

Analisando os valores das transações financeiras em 2007 no território brasileiro, podemos dizer que, na Região Concentrada, os valores referentes à concessão de crédito foram maiores que o volume de depósitos captados. Foram concedidos 712,68 bilhões de reais em crédito, enquanto foram coletados 618,57 bilhões de reais em depósitos. Configurando, portanto, uma "região ganhadora" de capital. O mesmo não ocorreu nas outras regiões do país. Todas as demais obtiveram um volume de depósitos maior do que de crédito concedido. A Região Nordeste recebeu 51,164 bilhões de reais em crédito no ano de 2007 e sua captação em depósitos foi de 73,23 bilhões de reais, sendo, portanto, a sua captação $30 \%$ maior em relação à concessão de crédito. Essa região apesar de contribuir em 2007 com a captação de 9,32\% dos depósitos em relação ao total nacional, recebeu, neste mesmo ano, apenas $6,06 \%$ dos créditos.

Cabe ressaltar que em 1997 o Nordeste, embora tenha contribuído com apenas 7,6\% dos depósitos, recebera $13,6 \%$ dos créditos, evidenciando uma lógica mais distributiva dos recursos financeiros no território. Segundo Contel (2006), podemos explicar essas mudanças, ao menos no caso do Nordeste, por meio de duas alterações: o fechamento dos bancos públicos, que ocorreu por intermédio de liquidações, federalização e privatizações, processos esses que aniquilaram as possibilidades de comando financeiro da região; e, não menos importante, a liquidação e venda do Banco Econômico, com sede na cidade de Salvador (BA).

Hoje, além da concentração financeira de crédito e depósito, o território brasileiro apresenta uma movimentação de dinheiro das áreas de rarefações financeiras para áreas de já altas densidades. As regiões Nordeste, Centro-Oeste e Amazônia são "regiões perdedoras" de capital, pois essas regiões captaram valores maiores de depósitos e receberam valores menores em crédito (Quadro 1).

\begin{tabular}{|c|c|c|c|}
\hline Região & $\begin{array}{c}\text { Crédito concedido (2007) em } \\
\text { bilhões de R\$ }\end{array}$ & $\begin{array}{c}\text { Captação de depósitos (2007) em } \\
\text { bilhões de R\$ }\end{array}$ & $\begin{array}{c}\text { Relação: } \\
\text { depósito/crédito em \% }\end{array}$ \\
\hline Concentrada & 712.683 & 618.578 & -13 \\
\hline Nordeste & 51.164 & 73.230 & 30 \\
\hline Centro-Oeste & 69.220 & 78.007 & 11 \\
\hline Amazônia & 12.250 & 15.344 & 20 \\
\hline & $\begin{array}{r}\text { Quadro 1: Relação depósito / crédito entre as regiões brasileiras - 2007 } \\
\text { Fonte: IBGE/Estados (2007). } \\
\text { Org.: Ricardo A. Scherma }\end{array}$ \\
\hline
\end{tabular}

Isso tudo muito se deve à permissividade e seletividade no uso do território. O crescente desmonte do controle público do território tem aprofundado as históricas desigualdades territoriais. No que se refere a repartição dos fluxos financeiros essas desigualdades devem se agravar, pois com a privatização da maior parte dos bancos estaduais, o destino financeiro dos estados da federação está subordinado à lógica seletiva e perversa das empresas financeiras. 


\section{A CIDADE DE SÃO PAULO: CENTRO FINAN- CEIRO DO TERRITÓRIO BRASILEIRO NA ATUALIDADE}

O processo de metropolização financeira em São Paulo (SANTOS; SILVEIRA, 2006) não é algo recente, vem se desenvolvendo desde o final dos anos 70 e é marcado por uma série de eventos que nos permitiram a análise das dinâmicas territoriais e foram estudados em nossa dissertação de mestrado. O estado de São Paulo, hoje, concentra densidades financeiras elevadas, se comparadas aos demais estados da federação. Como já dissemos no que se refere ao crédito, a concessão de 496 bilhões de reais representa 58,73\% do total nacional. A densidade de agências alcança uma agência para cada 6.721 habitantes e a concentração desses fixos no estado de São Paulo, em 2007, era de 6.017 agências, representando $34 \%$ do total nacional. Contudo, é na capital do estado, a cidade de São Paulo, o lugar onde encontramos as maiores densidades - 2177 agências bancárias; nesta cidade as operações de crédito em 2007 alcançaram 317.734 bilhões de reais, representando $64 \%$ do total do Estado e 37,5\% do total nacional; a captação de depósitos e poupanças alcançou 237.745 bilhões de reais, correspondendo a 21.838 mil reais por habitante e $30,30 \%$ do total nacional (IBGE/CIDADES, 2007). Mesmo quando comparamos esses dados com os da cidade do Rio de Janeiro, tradicional centro financeiro do país, evidencia-se a superioridade da capital paulista.

Além da enorme concentração de capitais, os conglomerados financeiros nacionais e estrangeiros procuram o Centro Metropolitano de São Paulo (CMSP) (CORDEIRO, 1992) para instalar suas sedes. A concentração das sedes de grandes corporações não é obra do acaso, está diretamente relacionada às vantagens locacionais encontradas em centros metropolitanos, entre elas, aquelas relacionadas ao grande fluxo de informações especializadas, minimização de custos operacionais, facilidade nos contatos face a face entre executivos de diferentes empresas e organizações, maior acesso a toda ordem de serviços corporativos e aproveitamento das amenidades urbanas (CORDEIRO, 1992, p.10).

Helena K. Cordeiro (1992), ao estudar a expansão do Centro Metropolitano de São Paulo, há dezoito anos, já apurava a importância do Centro Principal (Tradicional), e que ainda que o Centro Paulista, segundo a autora, se afirmasse como maior núcleo do sistema financeiro, já era evidente a constituição e movimento de dinamização em um corredor de sedes de empresas financeiras se desenvolvendo na Avenida Faria Lima.

Em 2005, o tecido urbano de São Paulo abrigava em três lugares distintos - o Centro Tradicional, a Avenida Paulista e o Quadrante Sudoeste - a maior parte das sedes das empresas financeiras do país. As previsões, quanto à expansão das sedes para o corredor na Avenida Faria Lima, analisada pela Professora Helena Cordeiro, concretizaram-se. Segundo Daniel Medeiros e Eliseu Spósito (2005, p.130), a Área Central concentrava em 2005, 12 sedes bancárias (13\%), enquanto que a região Paulista aglutinava 31 sedes (33\%) e o Quadrante Sudoeste apresentava-se com um total de 50 sedes ( $54 \%$ ).

Esses dados nos permitem assegurar que o estado de São Paulo apresenta hoje a maior concentração financeira do território nacional e sua capital, a cidade de São Paulo, afirma-se como centro financeiro do país. Como nos lembra Milton Santos: "Se muitas variáveis modernas se difundem amplamente sobre o território, parte considerável de sua operação depende de variáveis geograficamente concentradas" (SANTOS, 1998, p.90). É o caso das finanças. "A cidade de São Paulo assume, portanto, um papel estratégico, pois é o lugar sede da produção e do controle da nova vaga de modernizações que reorganiza o território nacional" (SILVA BERNARDES, 2006, p.429). Como nos explica Santos; Silveira (2006, p.303; 304), se o comando técnico das operações produtivas pode ser relativamente disperso pelo território em função da ampliação do meio técnico-científico-informacional o "comando propriamente político, que inclui a regulação normativa, financeira, informacional, tende a se concentrar em um número menor de lugares, sendo que no Brasil esse papel é realizado, sobretudo por São Paulo".

Em relação às sedes bancárias, sua presença em São Paulo permite que esses centros de controle possam usufruir de todas as possibilidades territoriais da Metrópole informacional, como por exemplo, proximidade com as agências de publicidade que 
lhes prestam serviço, como a Duailibi Petit Zaragoza Propaganda (DPZ), com escritório no Centro Metropolitano; essa é uma das mais importantes agências de publicidade do Brasil.

Em São Paulo, renomadas universidades oferecem toda uma sorte de cursos de graduação e pós-graduação voltados ao seguimento das finanças, formando anualmente dezenas de novos profissionais. É também nesta metrópole que se encontram hoje verdadeiros centros inteligentes, voltados à elaboração de uma racionalidade que permita a exploração eficaz dos pobres, como a Escola Superior de Propaganda e Marketing (ESPM), e a Fundação Getúlio Vargas (FGV), universidades que desenvolvem cursos de marketing e varejo que visam cooptar a população pobre urbana do país.

O Centro Metropolitano de São Paulo, onde se encontram as sedes das grandes empresas hegemônicas, bem como todo o aparato intelectual e informacional de que elas precisam, é o lugar onde parte das estratégias políticas de uso do território brasileiro é elaborada, condenando toda a sociedade a obedecer a lógicas e interesses corporativos. $\mathrm{O}$ aprofundamento e expansão do sistema de crédito, com altas taxas de juros, no Brasil podem ser considerados como um destes novos planos, em outras palavras, novas estratégias de uso do território pelo sistema financeiro.

\section{REFERÊNCIAS:}

ARROYO, M . Globalização e espaço geográfico. Experimental, São Paulo, n. 6, p. 15-31, 1999.

BENKO, Georges B; LIPIETZ, Alain. (Org.) As regiões ganhadoras. Distritos e redes. Os novos paradigmas da geografia econômica. Tradução de Antonio Gonçalves. Oeiras: Celta, 1994

CATAIA, M. A. As desigualdades e a tecnificação do território brasileiro. In: Ana Fani Alessandri Carlos. (Org.). Ensaios de geografia contemporânea. Milton Santos, obra revisitada. 1 ed. São Paulo: HUCITEC, 1996, v. 1, p. 170-177.

CONTEL, F. B. Território e Finanças: Técnicas, normas e topologias bancárias no Brasil. Tese (Dou- torado em Geografia Humana)- do Programa de Pós-Graduação em Geografia Humana da Universidade de São Paulo- Departamento de Geografia - FFLCH - USP, 2006.

CORDEIRO, Helena Konh. A "Cidade Mundial” de São Paulo e a Recente Expansão do seu Centro Metropolitano. Revista Brasileira de Geografia/ Fundação Instituto Brasileiro de Geografia e Estatística -n54(3) p.5 - 26. Rio de Janeiro. 1992.

DIAS, L. C. Por que os bancos são o melhor negócio no país? hegemonia financeira e geografia das redes bancárias. In: ALBUQUERQUE, E. S. (Org.). Que país é esse? Pensando o Brasil contemporâneo. São Paulo: Globo, 2005, p. 27-62.

GOMES, Cilene. Telecomunicações, Informática e Informação e a Remodelação do Território Brasileiro. Tese de Doutorado do Programa de Pós-Graduação em Geografia Humana da Universidade de São PauloDepartamento de Geografia - FFLCH - USP, 2001.

IBGE/ CIDADES. Instituto Brasileiro de Geografia e Estatística. Apresenta dados sobre as cidades brasileiras. Disponível em: < http://www.ibge.gov.br/ cidadesat/topwindow.htm?1> . Acessos em: 2007, 2008 e 2009.

IBGE/ ESTADOS. Instituto Brasileiro de Geografia e Estatística. Apresenta dados sobre os estados brasileiros. Disponível em: http://www.ibge.gov.br/estadosat/ . Acessos em: 2007, 2008 e 2009.

LABASSE, Jean. L'Espace Financier. Analyse Géographique. Chapitre 2. Les Localisations. Paris. Librairie Armand Colin.1974.

MEDEIROS, Daniel de S.; SPOSITO, Eliseu S. A territorialização do sistema bancário na metrópole paulistana. GEOUSP - Espaço e Tempo, São Paulo, n. 17, p.121-132, 2005.

MONBEIG, Pierre. Novos estudos de Geografia Humana Brasileira. São Paulo. Difusão Européia do Livro. 1957. 
RAMOS, S. F. Sistemas Técnicos Agrícolas e Meio Técnico Científico Informacional no Brasil.. In: SANTOS, M; SILVEIRA, M. L. (Org.). O Brasil: território e sociedade no início do século XXI. Rio de Janeiro: Record, 2006 [2001] , p. 375-387.

SANTOS, Milton. Natureza do Espaço: Técnica e Tempo. Razão e Emoção. São Paulo: Hucitec, 1996.

"O Espaço Geográfico como categoria Filosófica", In: Terra Livre - O espaço em questão, São Paulo: Marco Zero e AGB, 1998.
SANTOS; SILVEIRA, M. L. O Brasil: território e sociedade no início do século XXI. Rio de Janeiro: Record, 2006 [2001].

SILVA BERNARDES, A. M. . A nova divisão territorial do trabalho brasileira e a produção de informações na cidade de São Paulo (as empresas de consultoria). In: SANTOS, M; SILVEIRA, M. L.. (Org.). O Brasil: território e sociedade no início do século XXI. Rio de Janeiro: Record, 2006 [2001] , p. 413-432. 